\title{
Avaliação termográfica do boleto dos membros torácicos e pélvicos de cavalos Puro Sangue Inglês de corrida em início de treinamento
}

Hanna Caroline Prochno, Patricia Fernandes Rodrigues, Bianca Pegoraro Vieira, Rodolfo Augusto Althaus Jansen, Fernanda

Mendes Barussi, Fernanda Zettel Bastos, Pedro Vicente Michelotto Jr

Pontifícia Universidade Católica do Paraná (PUCPR), Curitiba PR, Brasil

*Autor correspondente

e-mail: michelottojunior@yahoo.com.br

\section{Resumo}

Lesões envolvendo a articulação do boleto, a maioria ocasionada por estresse acumulativo que pode envolver osso, cartilagem ou tecidos moles, estão entre as principais causas de interrupção no treinamento de cavalos de corrida. A termografia infravermelha, importante técnica auxiliar ao clínico de equinos, representa a temperatura da superfície corpórea, podendo sinalizar a ocorrência de injúrias pelas alterações na temperatura e fluxo sanguíneo, e permite identificar precocemente alterações, com detecção anterior à manifestação clínica de afecções locomotoras. Este trabalho tem como objetivo estudar a variação térmica das articulações metacarpofalangeanas (MC) e metatarsofalangeanas (MT) de cavalos jovens Puro Sangue Inglês (PSI) de corrida, no período inicial de treinamento. Foi procedida a avaliação termográfica em 16 cavalos PSI de corrida, com idade inicial entre 21 e 24 meses, machos e fêmeas, oriundos do Jockey Club do Paraná, em Curitiba. Os animais chegaram no stud em junho, e após um período de adaptação, foram iniciados no treinamento. As avaliações termográficas começaram juntamente com o início do treinamento na segunda quinzena de junho de 2016, e foram realizadas até a segunda quinzena de janeiro de 2017, fechando 7 meses de avaliação e 16 avaliações realizadas no total. As avaliações foram realizadas quinzenalmente tendo início às $6 \mathrm{~h}$, para que tivéssemos um mínimo de interferência pela temperatura ambiente. Foram realizadas com os animais em repouso dentro das baias, protegidos da luz e do vento. Todas as imagens foram capturadas com uma distância média de 1,5 metros do cavalo com o avaliador. Para captura das imagens foi utilizada uma câmera termográfica Flir E50bx, obtendo-se imagens pelos aspectos dorsal e palmar das articulações MC e MT, e selecionando um ponto médio no boleto em ambos os aspectos dorsal/palmar para a medição da temperatura a partir desses pontos. As imagens foram analisadas utilizando o software Flir Tools para registros de temperatura em graus celsius. A análise dos dados foi realizada através de ANOVA seguido por teste de Tukey de múltipla comparação, considerando significativo $\mathrm{P}<0,05$. 0 estudo foi aprovado pelo 
Comitê de Ética no Uso de Animais PUCPR, e registrado pelo número 951A. A temperatura das articulações MC e MT não diferiram entre o lado esquerdo e o direito em nenhuma das avaliações, sendo consideradas juntas para as análises entre os tempos de avaliação. Nos membros torácicos, as temperaturas da última avaliação foram significativamente maiores que a inicial em junho $(\mathrm{P}<0,0001)$, em ambos os aspectos, representando $6,88^{\circ} \mathrm{C}$ de acréscimo no aspecto dorsal e $8,24^{\circ} \mathrm{C}$ de acréscimo no aspecto palmar. Em relação aos membros pélvicos, na avaliação das articulações MT pela vista dorsal, as temperaturas também tiveram aumento significativo: $6,65^{\circ} \mathrm{C}$ na última avaliação em relação à primeira $(\mathrm{P}<0,0001)$. Na vista plantar $\mathrm{o}$ resultado foi similar e a elevação da temperatura foi de $7,13^{\circ} \mathrm{C}$ entre a primeira e última avaliação $(\mathrm{P}<$ 0,0001). Tais variações podem ser explicadas pela intensidade de treinamento, sendo que na primeira avaliação os animais estavam em início de treinamento ao trote e na última, estavam em trabalho intenso de $1.600 \mathrm{~m}$. A termografia foi capaz de mostrar modificações circulatórias na fase inicial da remodelação óssea e adaptação ao exercício. Com o aumento da intensidade do exercício possivelmente aumenta o fluxo sanguíneo periférico, aumentando a temperatura da superfície externa dos membros, que foi detectado com alta sensibilidade pelo exame termográfico. Os achados do presente estudo sugerem que a termografia é uma ferramenta útil para avaliar as alterações circulatórias em região de boleto de potros em início de treinamento, podendo ainda, em estudos futuros, ser utilizada na identificação de problemas subclínicos, evitando o aparecimento de lesões que possam interferir no desempenho atlético dos animais.

Palavras-chave: Articulações. Diagnóstico por imagem. Equinos. 